\title{
Influenza Viruses
}

\author{
Ilkay Bahceci (Corresponding author) \\ Recep Tayyip Erdogan University, Faculty of Medicine \\ Department of Medical Microbiology, Rize, Turkey \\ E-mail:bahceciie@hotmail.com
}

Sule Batcik

Recep Tayyip Erdogan University, Faculty of Medicine, Department of Anesthesiology and Reanimation, Rize, Turkey

E-mail:sule.batcik@erdogan.edu.tr

Leyla Kazancioglu

Recep Tayyip Erdogan University, Faculty of Medicine, Department of Anesthesiology and Reanimation, Rize, Turkey

E-mail:leyla.kazanc1oglu@erdogan.edu.tr

Hamiyet Busra Gundogdu

Recep Tayyip Erdogan University, Faculty of Medicine

Department of Medical Microbiology, Rize, Turkey

E -mail:hamıyetbusragullu@gmail.com

Ugur Kostakoglu

Recep Tayyip Erdogan University, Faculty of Medicine, Department of Infectious Diseases, Rize, Turkey E -mail:ugur.kostakoglu@erdogan.edu.tr

\begin{abstract}
Objective: The influenza viruses classified in the Orthomyxo viridae family have three types, A, B, C according to the irantigenic properties. Influenza A virus can lead to epidemics as well as pandemics with different subtypes depending on hemagglutinin and neuraminidase glycoproteins. Influenza viruses have been monitored by the World Health Organization (WHO) since 1952, due to their public health threat. In this study, it was aimed to determine the influenza data causing epidemics and loss of life in our country and in the world.

Method: During the 4 (four) year period from January 2016 to December 2019, samples were taken from patients with suspected SARI in the form of nasal swabs who applied to hospitals in our city's centers and districts with influenza-like symptoms. Turkey Public Health Microbiology Laboratory samples sent to the Virology Department were examined by molecular methods.

Findings: In 2016, 276 samples with SARI were examined; 128 (46.3\%) specimens were positive for influenza A and 117 (42.3\%) were negative. 17 (6.4\%) samples were identified as influenza B, while 14 (5\%) samples were identified as Rhinovirus. 65 (50.7\%) samples of influenza A patients were identified as influenza A (H1N1) pdm09 and 63 (49.3\%) samples as influenza A H3N2. Influenza A and Influenza B decreased significantly in 2017, 2018 and 2019.

Discussion and conclusion: It is a disease that changes every year in terms of influenza factors and effects. In line with this information, while the number of patients was quite high in 2016, Influenza A and Influenza B decreased significantly in 2017, 2018 and 2019. Molecular typing will be facilitated in that the influenza vaccine to be administered in the following year will include identification genictypes. As a result, individuals who are at risk should be vaccinated; necessary measures should be taken to prevent outbreaks; A sample should be taken from every patient suspected of SARI and examined in terms of influenza and molecular typing should be done.
\end{abstract}

Key words: Severe acute respiratory infection(SARI), influenza, epidemic 


\title{
İnfluenza (Grip) Sürveyans Verileri: 4 yıllık çalışma
}

\begin{abstract}
GÍRIŞ
Orthomyxoviridae familyası içerisinde sınıflandırılan influenza virüslerinin, antijenik özelliklerine göre A, B, C olmak üzere üç tipi vardır (1). İnfluenza A virüsü, yapısında yer alan hemaglutinin ve nöraminidaz glikoproteinlerine bağlı olarak farklı alt tipleri ile epidemilerin yanı sıra pandemilere de yol açabilmektedir (1). Dolaşımda 2 farklı soy şeklinde bulunan influenza B virüsü ise mevsimsel grip etkeni olarak karşımıza çıkmaktadır. İnfluenza C virüsü, dolaşımda tek bir soy hâlinde bulunur ve sporadik enfeksiyonlara neden olur $(1,2)$. İnfluenza virüsleri toplum sağlı̆ı̆ın tehdit eden özellikleri nedeni ile 1952 yllından beri Dünya Sağllk Örgütü (DSÖ) tarafindan izlenmektedir (3). Türkiye'de influenza sürveyans çalışmaları ise 2005 yılında Sağlık Bakanlığı öncülüğünde Ankara Refik Saydam Hıfzıssıhha Merkezi'ne bağlı Ulusal Viroloji Referans Merkez Laboratuvarı aracılığı ile yürütülmeye başlatılmıştır (4). Ayrıca 2015-2016 grip sezonunda Türkiye Halk Sağlığı Kurumu (THSK) şiddetli akut solunum yolu enfeksiyonları (SARI) sürveyans çalı̧̧malarını da başlatmış bulunmaktadır (5). Bu çalı̧̧mada dünyada ve ülkemizde salgınlara ve can kayıplarına neden olan influenza verilerinin bölgemiz de tespit edilmesi amaçlanmıştır.
\end{abstract}

\section{YÖNTEM}

2016 yılı Ocak ayından - 2019 yılı Aralık ayına kadar olan 4 ( dört ) yıllık süre içinde İnfluenza benzeri semptomlarla ilimiz merkez ve ilçelerindeki hastanelere başvuran, SARI şüphesi taşıyan hastalardan nazal sürüntü şeklinde örnekler alınmıştır. Bu kapsamda 2015-2016 ve ondan sonraki her sezonda influenza sürveyansı kapsamında ilimiz sağlık müdürlüğ̈̈ tarafından bölgedeki hastanelere dağıtılan taşıma besiyerleri yoluyla alınan nazal sürüntü örnekleri Virocult (Medical Wire Equipment CO, İngiltere) viral taşıma besiyeri içerisinde THSK bünyesinde faaliyet gösteren Ankara Refik Saydam Hıfzısıhha Merkezi Mikrobiyoloji Birimindeki İnfluenza Referans Laboratuvarına gönderilmiştir.Referans laboratuvarında SARI olgularına ait örneklerde influenza ile birlikte 21 solunum yolu virüsü FTD Respiratory pathogens 21 (fast-tract DIAGNOSTICS, Lüksemburg) kiti kullanılarak RotorGene 3000 (QIAGEN, Almanya) cihazında mültipleks realtime PCR yöntemi ile araştırılmıştır.

\section{BULGULAR}

2016 yılı içinde SARI olgusu şüphesi olan 276 örnek incelenmiş 128 ( \%46,3) örnek İnfluenza A pozitif saptanırken, 17 ( \% 6,4) örnek İnfluenza B, 14 (\% 5) örnek Rhino virüs olarak tespit edilirken, 117 ( \% $42,3)$ örnek ise negatif saptanmıştır. İnfluenza A tespit edilen 128 örneğin $65(\% 23,5)$ 'i influenza A (H1N1) pdm09, 63 (\% 22,8 )'ü influenza A H3N2 olarak tespit edilmiştir. Tespiti yapılan SARI olgusu 7 hasta ex olmuştur.

2017 yılı içinde SARI olgusu şüphesi olan 52 örnek incelenmiş 42(\% 80,7) tanesi negatif saptanırken 7 $(\% 13,4)$ örnek influenza A bunlarında $6(\% 11,5)^{\text {‘s }}$ influenza A (H1N1) pdm09, $1(\% 1,9)$ 'i influenza A H3N2 ve $3(\% 5,7)$ örnekte influenza B olarak tespit edilmiş̧ir.

2018 yllı içinde SARI olgusu şüphesi olan 43 örnek incelenmiş bunlardan 35 ( \% 81,3) tanesi negatif saptanırken, $6(\% 13,9)$ hastaya ait örnek influenza A bunlardan da $5(\% 11,6)$ tanesi (H1N1) pdm09, $1(\% 2,3)$ tanesi de influenza A H3N2 olmuştur, $2(\% 4,6)$ örnek ise İnfluenza B olarak tespit edilmiştir. 2019 yılı içinde SARI olgusu şüphesi olan 6 örnek incelenmiş olup $5(\% 83,3)$ tanesi negatif, $1(\%$ 16,4) tanesi de influenza A H3N2 olarak saptanmıştır.

\section{TARTIŞMA VE SONUÇ}

Mevsimsel grip genel olarak bilindiğinin aksine çok daha fazla sayıda hastanede yatışa ve ölüme neden olmaktadır (6,7). Mevsimsel Grip ve Respiratuvar Sinsityal Viruse (RSV)'ye bağlı hastane yatı̧sının araştırıldığı çalışmalarda RSV'ye bağlı yatışların yıldan yıla pek değişiklik göstermediği oysa mevsimsel grip,( influenzaya) bağlı yatışların dolaşımdaki virüs suşunun virülansına ve toplumdaki duyarlı popülasyonun oranına bağlı olarak yıldan yıla oldukça değişkenlik gösterdiği belirtilmektedir $(8,9)$. Bizim çalışmamızda göstermiştir ki 2016 dan 2019 kadar olan süre içinde Influenza görülme oranı anlamlı derecede düşmüştür. 2016 yılında İnfluenza A(H1N1) \% 23,5 2017 ve 2018 de \% 11,6 2019 da 
ise \% 0 oranında saptanmıştır. influenza A H3N2 ise 2016 yılında \% 22,8 2017 de \% 1,9 2018 'de \%2,4 2019 da ise \% 16,4 oranında görülmüştür.2019 yılı içindeki yükseklik tek vaka olarak tespit edilmesinden kaynaklanmıştır. 2019 yılını göz ardı edersek İnfluenza A H3N2 de düşme eğilimi göstermiştir. İnfluenza B ise 2016 yılında \% 6,4 2017 yılında \% 5,7 2018 yılında \% 4,6 2019 yılında ise \% 0 olarak görülmüştür. Influenza B deki yıllara göre düşüş de oldukça belirgindir. İnfluenza virüsleri ani olarak başlayan 37.8'in üzerinde ateş, hâlsizlik, kas ağrısı, öksürük, boğaz ağrısı gibi belirtilerle karakterize grip hastalığına neden olur $(10,11)$. Grip etkenleri ve etkileri bakımından her yıl değişkenlik gösteren bir hastalıktır (12). Her yıl dünyada 3-5 milyon kişide ağır seyreden ve 250-500 bin kişide ölümle sonuçlanan influenza kaynaklı hastalık tabloları ile karşılaşılır (13). Bölgemizde elde edilen veriler gözden geçirildiğinde 2016 ve sonraki yıllarda grip sezonunda influenza A (H1N1) pdm09 ve influenza A H3N2 oranları hemen hemen eşit olarak tespit edilmiştir.2016 yılında hasta kayıpları yaşanırken, 2019 yılında hasta kaybı olmamıştır.

Grip ile mücadelede aşı ile birlikte o bölgedeki sürveyans çalışmaları da önemlidir. Gribin aktivasyon zamanının tespiti salgınları önlemek açısından önemlidir. Moleküler tiplendirme bir sonraki yıl uygulanacak grip aşısının belirlenen antijenik tipleri içermesi adına kolaylaştırıcı olacaktır

Sonuç olarak risk taşıyan bireyler mutlaka aşılanmalı, salgınları önlemek için gerekli tedbirler alınmalı, SARI şüphesi taşıyan her hastadan örnek alınmalı ve İnfluenza açısından incelenip moleküler tiplendirme yapılmalıdır. Moleküler tiplendirme antiviral etkinliği saptama açısından önemlidir. Sürveyans çalışmaları geliştirilmelidir.

Tablo 1: 4 yıllık İnfluenza verileri

\begin{tabular}{|c|c|c|c|c|c|}
\hline & 2016 & 2017 & 2018 & 2019 & Toplam \\
\hline $\begin{array}{l}\text { İnfluenza A } \\
\text { (H1N1) }\end{array}$ & $65(\%$ 23,5) & $6(\% 11,6)$ & $5(\% 11,6)$ & $0(\% 0)$ & $76(\% 20,1)$ \\
\hline $\begin{array}{l}\text { İnfluenza A } \\
\text { (H3N2) }\end{array}$ & $63(\% 22,8)$ & $1(\% 1,9)$ & $1(\% 2,4)$ & $1(\% 16,6)$ & $66(\% 17,5)$ \\
\hline İnfluenza B & $17(\% 6,4)$ & $3(\% 5,7)$ & $2(\% 4,6)$ & $0(\% 0)$ & $22(\% 5,8)$ \\
\hline Negatif & $131(\% 47,3)$ & $42(\% 80,6)$ & $35(\% 81,4)$ & $5(\% 83,4)$ & $213(\% 56,4)$ \\
\hline Toplam & 276 & 52 & 43 & 6 & $377(\% 100)$ \\
\hline
\end{tabular}

\section{Kaynaklar}

1.Puig-Barber J, Tormos A, Trushakova S, et al. The Global Influenza Hospital Surveillance Network (GIHSN): A new platform to describe the epidemiology of severe influenza. Influenza Other Respir Viruses 2015; 21. doi: 10.1111/irv.12335

2. Biere, B., Bauer, B. \& Schweiger, B. Differentiation of influenza B virus lineages Yamagata \& Victoria by real-time PCR. J. Clin. Microbiol. 48, 1425-1427 (2010).

3.Influenza (Seasonal), Fact sheet [homepage on the Internet]. World Health Organization [updated March 2019; cited 29 February 2020]. Available from: http://www.who.int/mediacentre/ p : 31 /en/: March 202020 /ISBN : 978-92-4-151532-0 /

4. www.saglik.gov.tr. Grip (İnfluenza) Vakalarına İlişkin Açıklama (06.01.2020)

5. İnfluenza Vaka Yönetim Algoritması [homepage on the Internet]. Türkiye Halk Sağlığ1 Kurumu [cited 21 February 2016]. Available from:http://grip.gov.tr/saglik-personeli-icin-bilgiler/282influenza-vaka-yonetim-algoritmasi.html 
6. Ortiz JR, Neuzil KM, Shay DK, et al. The burden of influenza-associated critical illness hospitalizations. Crit Care Med 2014;42(11):2325-32.

7. Ortiz JR, Neuzil KM, Cooke CR, Neradilek MB, Goss CH, Shay DK. Influenza pneumonia surveillance among hospitalized adults may underestimate the burden of severe influenza disease. PLoS One 2014;25;9(11):e113903.

8. Zhou H, Thompson WW, Viboud CG, et al. Hospitalizations associated with influenza and respiratory syncytial virus in the United States, 1993-2008. Clin Infect Dis 2012;54(10):1427-36.

9. Chaves SS, Aragon D, Bennett N, et al. Patients hospitalized with laboratory-confirmed influenza during the 2010-2011 influenza season: Exploring disease severity by virus type and subtype. J Infect Dis 2013;208(8):1305-14.

10. Lehnert R, Pletz M, Reuss A, et al. Antiviral medications in seasonal and pandemic influenza. Dtsch Arztebl Int. 2016;113(47):799-807.

11. Metersky ML, Masterton RG, Lode $H$, et al. Epidemiology, microbiology, and treatment considerations for bacterial pneumonia complicating influenza. Int J Infect Dis. 2012;16(5):e3213

12. Suntur B.M, Kaya H, Kuşçu F, Experience of a seasonal influenza epidemic, Ege Tıp Dergisi /Ege Journal of Medicine 2018;57(1):46-50

13. Boikos C, Caya C, Doll MK, et al. Safety and effectiveness of neuraminidase inhibitors in situations of pandemic and/or novel/variant influenza: a systematic review of the literature, 200915. J Antimicrob Chemother. 2017;72(6):1556-1573 